\title{
The Integrated Clinical Curricular Unit in the Dental Medicine Graduation: Reflections on It Importance for the Students
}

\author{
L.Miguel Carreira ${ }^{1,2,3,4}$ \\ ${ }^{1}$ Faculty of Veterinary Medicine, University of Lisbon (FMV/ULisboa)-Portugal \\ ${ }^{2}$ Centre for Interdisciplinary Research Animal Health (CIISA) - FMV/ULisboa - Portugal \\ ${ }^{3}$ Anjos of Assis Veterinary Medicine Centre (CMVAA), Barreiro - Portugal \\ ${ }^{4}$ Human Dental Clinical, Lisboa - Portugal
}

\begin{abstract}
Integrated Clinical (IC) curricular unit of the Dental Medicine graduation, should be considered as a fundamental axis in the Dental Medicine Curricula at the colleges, and never, as a complementary or terminal curricular unit. Characterized by a pedagogical conception of integrated teaching of medical and dental sciences curriculum, the IC unit should allow the students to access the opportunity to interrelate the theoretical and practical knowledge learned during the course. Its main aim should be the graduation of general dentists, approaching the students to the daily routine of dental practitioner, enabling them to provide to the patient an ethical, comprehensive, and efficiently integrated treatment plan.
\end{abstract}

Keywords: Student; Patient; Graduation; Integrated Clinical; Curricula

\section{The Integrated Clinical (IC) CuRricular Unit}

The Integrated Clinical (IC) curricular unit of the dental medicine graduation, should always be characterized by rewarding in its pedagogical conception the integrated teaching of medical and dental sciences curriculum, allowing the students the opportunity to interrelate the theoretical and practical knowledge learned during the course, thus avoiding the emergence of a premature specialization in the future dentists.

Its main aim should be the graduation of general dentists, approaching the students to the daily routine of dental practitioner, enabling them to provide to the patient an ethical, comprehensive, and efficiently integrated treatment plan.

A high quality treatment plan adjusted to the patient directly depends from the medical and dental student skills acquired during the course. The ability to make a good clinical history, to establish diagnoses, and to planning and execute multidisciplinary dental procedures in an integrated approach, always respecting the needs and the motivation of the patient, is associated with a more favorable prognosis with the potential recovery of the stomatognatic apparatus functionality. The IC should also promote in the student the ability to develop it interpersonally communicate skills with the patient and the colleagues.

The board of professors in the IC curricular unit should be considered as the pillar of the unit. It should be the more heterogeneous as possible, constituted by teachers from the different dental specialties, and with good critical and pedagogue's capacities, allowing to the student to develop high levels of quantity and quality work in minimum period of time. They should be seen by the student as an important technical support that helps to make a judicious judgment of the developed treatment plan and the type of dental procedures carried out. As a result, the student will assimilate in a more conscientious and appropriate way it clinical experience with patients, overcoming the difficulties when they are exposed to more serious and differentiated pathologies and clinical conditions, such as, periodontal and endodontic complex lesions, differentiated surgeries, or even, orthodontic corrections, which demands the presence of dental specialists.

Efficiency and effectiveness of the IC curricular unit teaching system can and should be evaluated by the productivity and quality of the work, that each student develop in the patients, which is directly associated with the level of theoretical and practical knowledge acquired throughout the course. 
Parameters such as, the level of medical record achievement by the students; the levels of the patient satisfaction, attendance, return and lack of consultations and treatments; the identification of the interrupted treatments, and the phase in which those interruptions occurred. These are examples, of some easy-to-record items that may help to understand the success of the IC curricular unit system in teaching. By considering these kind of items, it is possible to approach the IC curricular unit programs, in order to achieve what is intended for the dental student training at the end of the course.

Of great importance in the success of the IC curricular unit is the type of patient to whom the student has access, since the patient is the key to successful treatment. The ideal patient for IC curricular unit is the one who presents different needs regarding it oral health. It should require several dental procedures associated with at least a minimum of three different specialties', and with different levels of complexity. However, those clinical conditions must be able to be solved by the students in a general clinical context, always under the teacher supervision. Patients who are not motivated and who discontinue their treatment plan are not considered as good patients to be accepted and integrated into the patient list of the IC curricular unit. The reason for this is that they do not allow the student to apply the scientific method for whom it has been trained, neither to carry out collective interventions, or even, to decide on the rationalization / clinical technique basis to be applied; thus interfering in the dental-biological training of the future dentist. The patient should stimulate in the student the capacity to establish correlations between the various presented and diagnosed oral pathologies, creating a notion of a organized unity in a successive way which presents a increasing level of complexity, based on the student theoretical and practical knowledge learned throughout the course. Prosthetic rehabilitation, restorative dentistry, peridonthology, and preventive and community dental medicine, are the main areas of action for the IC curricular unit.

\section{CONCLUSION}

Integrated Clinical curricular unit should be considered as a fundamental axis in the Dental Medicine Curricula at the colleges, and never, as a complementary or terminal curricular unit. It should be recognize as a starting point of the work from which is possible to develop different techniques and procedures related to each of the pathologies diagnosed, associated and considered at the patient's treatment plan, offering to the student the possibility of performing a fundamental analysis of his educational process which is revealed by the performance provided to the patient, through the multiplicity of general and specialties procedures practice, which results from the need to integrate all the knowledge acquired during the graduation, allowing to follow the patient from the initial triage process, until the final total oral rehabilitation.

\section{ACKNOWLEDGMENTS}

The author thanks CIISA - Centre for Interdisciplinary Research in Animal Health, of Faculty of Veterinary Medicine, University of Lisbon (FMV-ULisboa), Portugal; and Anjos of Assis Veterinary Medicine Centre (CMVAA), Barreiro, Portugal.

The author wishes to thanks to the Editor of the ARC Journal of Dental Sciences for his support allowing having this ARC-Free article submission.

\section{CONFLICT OF INTEREST STATEMENT}

The author declare that they have no conflict of interest. This research received no specific grant from any funding agency in the public, commercial, or not-for-profit sectors.

\section{REFERENCES}

[1] Hendricson, W.D.; Peter, M.S.; Cohen, A. Future Directions in Dental School Curriculum, Teaching, and Learning. American Association of Dental Schools. 75th Anniversary Summit Conference

[2] Hendricson, W.D., Payer, A.F., Rogers, L.P., et al. (1993). The medical school curriculum committee revisited. Acad Med 1993; 68:183-88. 94.

[3] Goffee, R., Jones, G. (1996). What holds the modern company together? Harvard Bus Rev; 74:133-48.

[4] Nowlin, T., Dodge, W., Hendricson, W.D. (1998). Results of a pilot patient-centered clinical education program. J Dent Educ; 62:106 
[5] Stacey, M.A., Morgan, M.V., Wright, C. (1998). The effect of clinical targets on productivity and perceptions of clinical competence. J Dent Educ; 62:409-14. 87.

[6] Mennin, S.P., Krackov, S.K. (1998). Reflections on relevance, resistance and reform in medical education. Acad Med; 73 (9): S60-S64.

[7] Fincham, A.G., Baehmer, R., Chai, Y., et al. (1997). Problem-based learning at the University of Southern California School of Dentistry. J Dent Educ; 61:417-25. 62.

[8] Berkson, L. (1993). Problem-based learning: have the expectations been met? Acad Med;68(10):79-88

[9] Chambers, D.W., Geissberger, M. (1997). Toward a competency analysis of operative dentistry techniques. J Dent Educ; 61:795-803. 40.

[10] Greene, J.C. (1997). Science and the shifting paradigm in dental education. J Dent Educ; 61:40711.

[11] Valchovic, R.W. (1997). Making science clinically relevant. J Dent Educ; 61:434-6.

[12] Field, M.J. (1995). Dental education at the crossroads: challenges and change. Washington, DC: National Academy Press, 1995.

[13] Jeffcoat, M.K., Clark, W.B. (1995). Research, technology transfer, and dentistry. J Dent Educ; 59:169-84.

[14] Reis, S.C.G.B.; Santos, L.B.; Leles, C.R. (2011). Clínica Integrada de Ensino Odontológico: Perfil dos Usuários e Necessidades Odontológicas. Rev Odontol Bras Central;20(52)

[15] White, A.B., Caplan, D.J., Weintraub, J.A. (1995). A quarter century of changes in oral health in the United States. J Dent Educ; 59:19-60

[16] Junges, R.S., Silveira, R., Portella, F.F., Rösing, C.K.,Samuel, S.M.W. (2011). Impact of the implantation of a new curriculum in the process of learning in a Faculty of Dentistry in Brazil. Brazilian Oral Research, 25(6), 478-484. https://dx.doi.org/10.1590/S180683242011000600002

[17] Rösing, C.K., Oppermann, R.V., da Silva, D.T., Deon, P., Gjermo, P. (2008). Student's appraisal of their dental education related to basic sciences learning: a comparison of four curricula in Norway and Brazil. Rev Odonto Ciênc.;23(3): 234-7

[18] Milani P.A.D. (2003). Avaliação e produtividade da disciplina de Clínica Integrada do Curso de Odontologia da Universidade Tuiuti do Paraná (Contribuição ao modelo de ensino odontológico). [Dissertação de Mestrado]. São Paulo. Universidade de São Paulo, Brasil

[19] Rösing, C.K., da Silva, D.T., Deon, P., Oppermann, R.V., Gjermo, P. (2009). Evaluation of 4 dental curricula based on student's expectations and satisfaction - report of Brazilian and Norwegian experiences. Rev ABENO;9(2):88-94

[20] Divaris, K., Barlow, P.J., Chendea, S.A., Cheong, W.S., Dounis, A., Dragan, I.F. et al. (2008). The academic environment: the students' perspective. Eur J Dent Educ.;12 (1):120-30

[21] Lynch, C.D., Wilson, N.H. (2010). Teaching of direct posterior resin composite restorations in UK dental therapy training programmes. Br Dent J. 8;208(9):415-21

[22] Jetursson, B.E., Lang, N.P. (2008). Prosthetic treatment planning on the basis of scientific evidence. J Oral Rehabil.;35 (1):72-9

[23] Haden, N.K., Andrieu, S.C., Chadwick, D.G., Chmar, J.E., Cole, J.R., George, M.C., et al. (2006). The dental education environment. J Dent Educ.;70(12):1265-70

[24] Haden, N.K., Hendricson, W.D., Kassebaum, D.K., Ranney, R.R., Weisntein, G., Anderson, E.L., et al. (2010). Curriculum change in dental education, 2003-09. J Dent Educ.;74(5):539-57

[25] Carreira, L.Miguel. (2014). The Use of Microsurgery for the Excellence Performance in the modern Dental Medicine Specialties. Master Science Thesis, for graduation in Human Dental Medicine, Egas Moniz Health Sciences Institute - Caparica -Portugal

[26] Institute of Medicine. (US) Committee on the Future of Dental Education; Field MJ, editor. Dental Education at the Crossroads: Challenges and Change. Washington (DC): National Academies Press (US); (1995). 4, The Mission of Education. Available from: https://www.ncbi.nlm.nih.gov/books/NBK232252/ 


\section{L.Miguel Carreira}

[27] Barnett, R. (2005). Reshaping the university: new relationships between research, scholarship and teaching. Maidenhead: SRHE and OUP, 2005

[28] Paganelli, A.P.C., Lima, A.S., Freitas, K., Beloti, A.M. (2003). Avaliação qualitativa das necessidades odontológicas dos pacientes da clinica integrada de adulto do curso de odontologia de CESUMAR. Iniciação Cientific;5(1):35-40

[29] Hutchings, P. (2003). Opening lines: approaches to the scholarship of teaching and learning. Menlo Park: Carnegie Foundation for the Advancement of Teaching,

[30] McLean, M. (2006). Pedagogy and the university: critical theory and practice. p 45. London and New York: Continuum

[31] Falchikov, N. (2005). Improving assessment through student involvement: practical solutions for aiding learning in higher and further education. London: Routledge

[32] Tedesco, L.A. (1995). Issues in Dental Curriculum Development and Change. J Dent Educ.;59(1):97-148.

[33] Sweet, J., Sweet, D. et al. (2008). Inter-professional learning and teaching in the dental workplace with physiotherapy, occupational therapy and dental undergraduates exchanging posture, ergonomic and oral health advice. AMEE; Prague, August 30 - September 3

[34] Della, F., Colin, C. (2005). Medical Education: Developing A Curriculum For Practice: Developing a Curriculum for Practice. McGraw-Hill Education (UK)

[35] Manogue, M., McLoughlin, J., Cecilia, C., Eilis, D., Christina, L., Meta, S., Alphons, P. (2010). Curriculum Structure, Content, Learning and Assessment in European Undergraduate Dental Education. Association for Dental Education in Europe Task Force II. ADEE General Assembly on 27th August. Accessed at: www.adee.org 